\title{
Multidimensional sensitivity study of the fuzzy risk assessment module in the life cycle of building objects
}

https://doi.org/10.1515/eng-2018-0059

Received April 20, 2018; accepted September 27, 2018

\begin{abstract}
The main purpose of this paper is to check the correctness of the operation of "the fuzzy risk assessment module in the life cycle of building objects". The authors examine sensitivity of the module to the possible change of parameters that may affect the final result of the calculations due to modification: sets of membership functions for input and output variables, rules of fuzzy implication to the process of aggregation of premises and aggregation of result conclusions, as well as methods for defuzzification the resultant value. All 99 combinations of input variable values were simulated taking into account the combination for: 4 sets of membership functions (polygonal, complex, harmonic and Gaussian dunctions), 4 sets of T-norms and S-norms (minimum and maximum of Mamdani, algebraic product and sum, product and sum of Hamacher, and product and sum of Einstein) and 2 defuzzification methods (centre of gravity and bisector area method). The authors calculated arithmetic average $(m)$, standard deviation $(s)$ and coefficient of variation $(V)$, which is a relative measure of variation for each of the 3168 combinations. Based on the results of research, the authors recommended the most appropriate sets of parameters that may affect the final result of the calculations.
\end{abstract}

Keywords: risk assessment, life cycle, building object, fuzzy sets, sensitivity study

\footnotetext{
${ }^{\star}$ Corresponding Author: Damian Wieczorek: Tadeusz Kościuszko Cracow University of Technology, Faculty of Civil Engineering, Warszawska 24, 31-155 Cracow, Poland;

E-mail: dwieczorek@ztob.pk.edu.pl

Edyta Plebankiewicz: Tadeusz Kościuszko Cracow University of Technology, Faculty of Civil Engineering, Warszawska 24, 31-155 Cracow, Poland; E-mail: eplebank@ztob.pk.edu.pl
}

\section{Introduction}

An attempt to reduce costs incurred in the life cycle of building objects is one of the ways to implement the environmental dimension of the European Union Sustainable Development Strategy in the industry sector, which includes construction (COM, 2003). The issue of life cycle cost of building objects is often addressed by scientists from around the world, as seen in numerous publications, such as (Aye, Bamford, Charters, \& Robinson, 2000; Hasan, Vuolle, \& Siren, 2008; Marszal, \& Heiselberg, 2011; Plebankiewicz, Zima, \& Wieczorek, 2016; Yi, \& Wen-jie, 2009).

Life cycle cost analysis of building objects is a calculation in nature; therefore, it should take into account the impact of risk in the estimated value. This vital issue is the focus of the ISO standard 15686-5:2008 "Buildings and constructed assets. Service life planning: Life cycle costing” (ISO 15686-5, 2008). This standard emphasizes that there exists no method for estimating the life cycle cost of building objects taking into account the impact of risk, which would be based on expert knowledge.

With this issue in mind, the authors of (Plebankiewicz, \& Wieczorek, 2016) presented their own solution, namely a fuzzy approach to the expert assessment of risk factors identified in the life cycle of building objects in the context of their impact on the amount of the building object life cycle cost. "The fuzzy risk assessment module in the life cycle of building objects" proposed by Plebankiewicz and Wieczorek was built on the basis of a fuzzy interpretation of two risk-specific input variables, i.e. probability of a unwanted phenomenon and effect of its occurrence. Due to the small number of input variables, and thus as small number of inference rules as possible, to construct their model the authors used assumptions in line with the fuzzy model of inference of Mamdani (Mamdani, 1974; Mamdani, 1977).

The purpose of the research described in this paper is to check the correctness of the operation of the fuzzy risk assessment module. The authors examine its sensitivity to 
the possible change of parameters that may affect the final result of the calculations. The scope of research concerns the analysis of the variability of the results obtained due to modification: sets of membership functions for input and output variables, rules of fuzzy implication to the process of aggregation of premises and aggregation of result conclusions, as well as methods for defuzzification the resultant value.

\section{The fuzzy risk assessment module in the life cycle of a building object}

As the risk definition according to work holds, (Skorupka, 2007), the risk is the probability of an adverse event occurring during the implementation of a construction project in a product with the consequence of its occurrence.

The fuzzy risk assessment module is built in accordance with the above-mentioned definition, namely one based on two risk-specific criteria (input variables): $x_{1}$ probability of a unwanted phenomenon $-P R(U p h)$ and $x_{2}$ - effect of occurrence of a unwanted phenomenon EFF(Uph).

Ambiguity and imprecision that often accompanies risk data is in the form of fuzzy information. Therefore, it was decided to use the theory of fuzzy sets in order to create an inference mechanism for risk factors.

The risk assessment expert is obliged to provide the input with sharp values of input variables $x_{1}{ }^{*} \mathrm{i}{x_{2}}^{{ }^{*}}$, which represent the risk factor identified in the life cycle of a building object. Then, as a result of the succession of fuzzification processes, inference and defuzzification, the value of the output variable $y$ will be calculated. The sharp value of the output variable $y^{\star}$ will indicate the answer to the risk assessor's request for including the impact of the identified risk factor on a given component of the life cycle cost of a building object - IRF(Uph).

\subsection{Fuzzification}

In the fuzzy risk assessment module both types of variables (input variables $x_{1}$ i $x_{2}$ and output variable $y$ ) are variables described linguistically. Thus, these variables assume real values (sharp). This means that families of all fuzzy sets $L(X), L(Y)$ which are defined for each variable, should be specified in numerical universals (domains) $U$ for input variables and $V$ for the output variable.
To describe the linguistic values, in the fuzzification block the following four groups of fuzzy sets membership functions were used. They include the following:

- polygonal functions (piecewise linear) - internal symmetrical triangular functions and external left and right of classes $L$ and $\Gamma$, respectively (basic set),

- complex functions (linear quadratic) - internal symmetrical functions of the $\Pi$ class and external left and right of classes $Z$ and $S$, respectively (alternative set I),

- harmonic functions - internal and external symmetrical functions left and right (alternative set II),

- Gaussian functions - symmetrical internal and external left and right (alternative set III).

Each of the above-mentioned types of membership functions can be described by mathematical formulas on the ranges of numerical universals $U$, which are limited by certain parameters responsible for the shape of a given membership function. In the literature on the subject, one finds publications (Kacprzyk, 2001; Piegat, 2003) providing formulas for the membership function indicating such parameters as: left and/or right ends of the universe interval $U\left(a, a^{\prime}\right)$, mode $(c)$ and/or arguments with the average (half) degree of membership $\left(b, b^{\prime}\right)$.

When constructing the fuzzy risk assessment module, the selection of parameters shaping the membership functions consisted in searching for such parameter values $a$, $a^{\prime}, b, b$ and $c$ (or their intervals) that the following conditions are fulfilled:

- the value of the maximum membership degree for item $x=c$ is exactly 1 , that is $\mu_{A}(c)=1$,

- values of membership degrees for elements $x=b$ and $x=b$, are exactly or approximately 0,5 , that is $\mu_{A}(b)=$ $\mu_{A}\left(b^{\prime}\right)=0,5$ or $\mu_{A}(b)=\mu_{A}\left(b^{\prime}\right) \cong 0,5$,

- values of membership degrees for elements $x=a$ and $x=a$ ' are exactly or approximately 0 , that is $\mu_{A}(a)=$ $\mu_{A}\left(a^{\prime}\right)=0$ or $\mu_{A}(a)=\mu_{A}\left(a^{\prime}\right) \cong 0$,

where: $A$ - exemplary fuzzy set.

For example, for a symmetric internal harmonic membership function, the formula for the function is as follows:

$\mu_{A}(x)=\left\{\begin{array}{lr}0,5\left[1+\cos \left(\Pi \frac{x-c}{\frac{b}{2}}\right)\right], & a \leqslant x \leqslant a^{\prime} \\ 0, & \text { outside above section }\end{array}\right.$

where: $c$ - modal value, $b=\frac{a+c}{2}$ and $b^{\prime}=\frac{a^{\prime}+c}{2}$, and length of sections $|c-a|=\left|c-a^{\prime}\right|$, and for the Gaussian symmetric internal function:

$$
\mu_{A}(x)=e^{\frac{-(x-c)^{2}}{2 \sigma^{2}}}
$$


where: parameter designations according to formula (1), and besides $\sigma$ - width of curve distribution.

Polygon functions are the most commonly used membership functions in this type of fuzzy inference models. The advantage of polygonal functions is their simple construction and a limited number of parameters describing the shape of the function.

A graphical interpretation of all sets of membership functions for input variables $x_{1}$ and $x_{2}$ is presented in figures from Figure 1 to Figure 8, respectively.

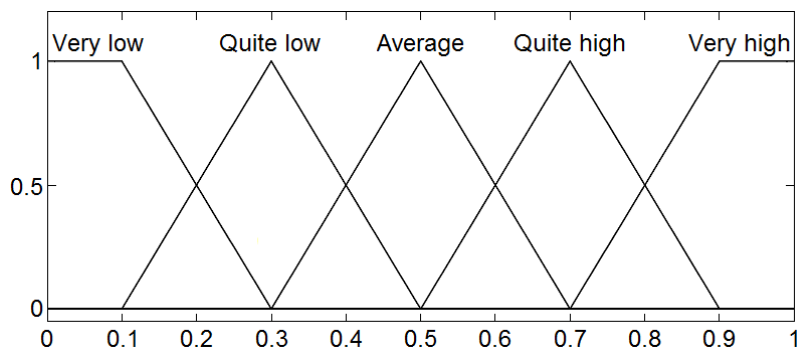

Figure 1: Membership function for the input variable $x_{1}-P R(U p h)$, polygonal functions (piecewise linear)

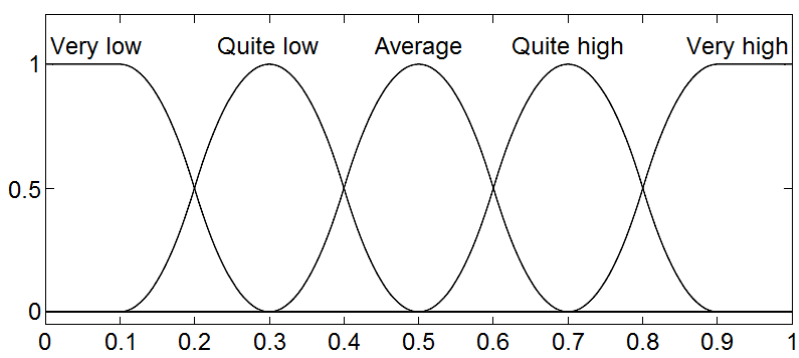

Figure 2: Membership function for the input variable $x_{1}-P R(U p h)$, complex functions (linear quadratic)

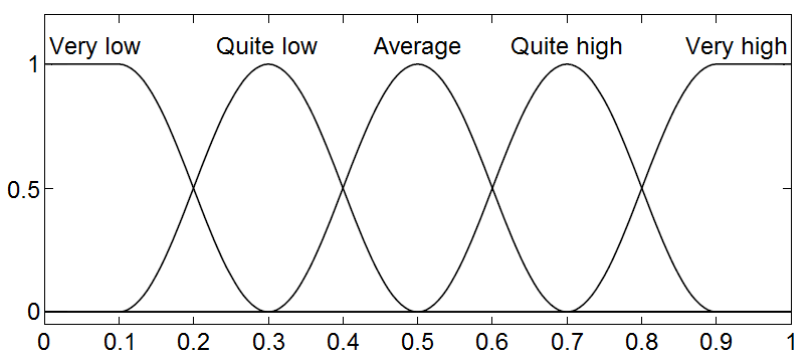

Figure 3: Membership function for the input variable $x_{1}-P R(U p h)$, harmonic functions

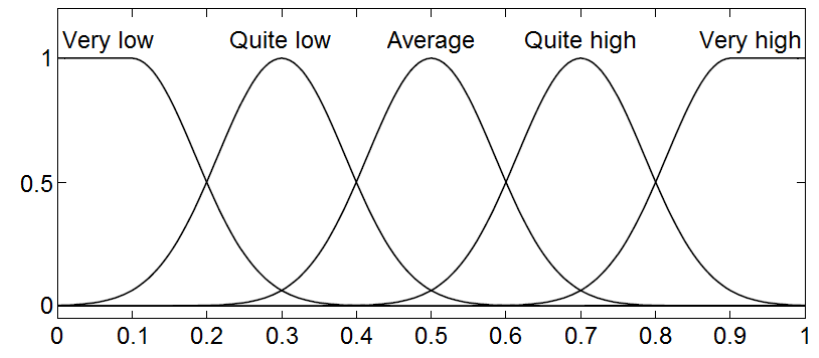

Figure 4: Membership function for the input variable $x_{1}-P R(U p h)$, Gaussian functions

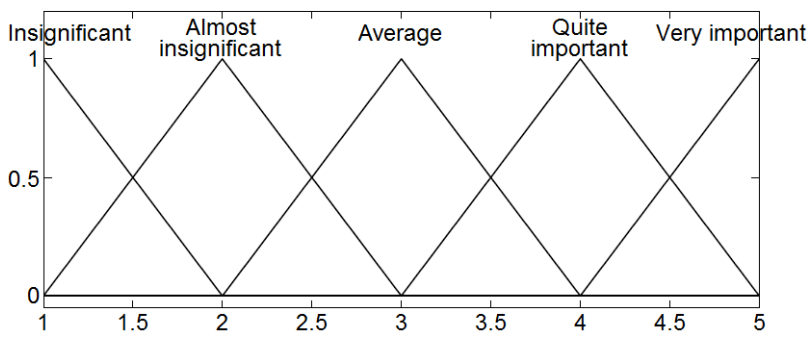

Figure 5: Membership function for the input variable $x_{2}-E F F(U p h)$, polygonal functions (piecewise linear)

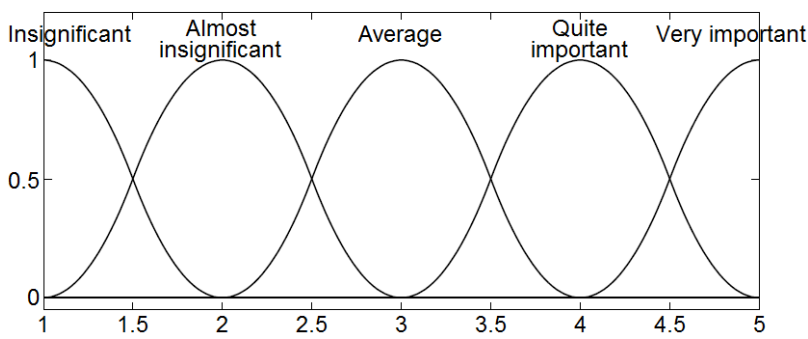

Figure 6: Membership function for the input variable $x_{2}-\operatorname{EFF(Uph),}$ complex functions (linear quadratic)

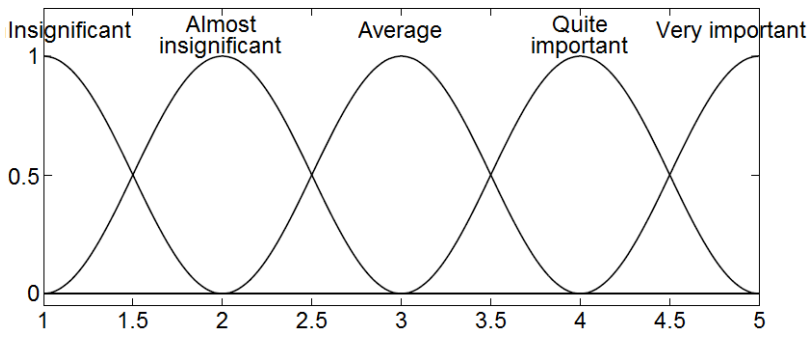

Figure 7: Membership function for the input variable $x_{2}-E F F(U p h)$, harmonic functions

\subsection{Inference}

The task of the inference block in models based on the assumptions of the Mamdani fuzzy model of inference (Mamdani, 1974; Mamdani, 1977) is the calculation of the resultant membership function for the output variable $\mu_{\text {res }}(y)$ based on membership levels for the values of sharp 


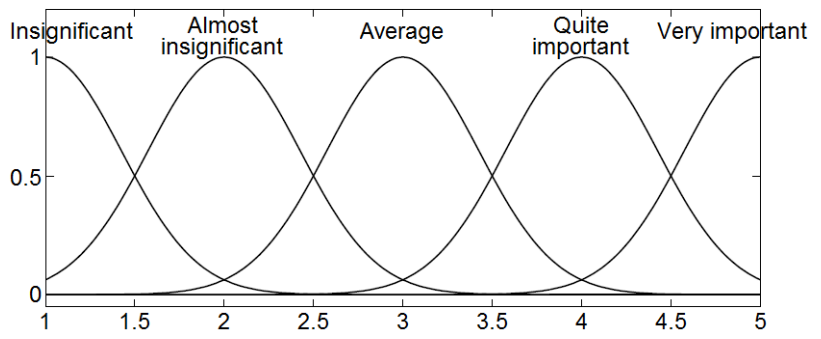

Figure 8: Membership function for the input variable $x_{2}-E F F(U p h)$, Gaussian functions

input variables $x_{1}{ }^{*} \mathrm{i} x_{2}{ }^{*}$. This function often has a complex shape and its calculation is performed by means of the process of inference.

The inference block forms the basic two elements, namely the rule base and the inferential mechanism.

The rule base developed within the fuzzy risk assessment module has a form of a conjunction due to the use of the operator „And”. It consists of 25 rules presented in Table 1. The main assumption when designing the rule base was that with the increase of the probability and the effect of an adverse event, the impact of the identified risk factor on the size of the corresponding component of the life cycle cost of the building is to grow in a gentle (non-stop) manner.

The operation of the inferential mechanism is, in turn, based on three consecutive mathematical operations: aggregation of simple premises, implications of fuzzy inference rules and aggregation of the conclusions of all rules.

Aggregation of simple premises concerns the calculation of the degree of truth of a fuzzy rule created by premises. The degree of truth is understood here as the degree of membership to a given relation $R_{N}$ fuzzy values of sharp input variables $x_{1}{ }^{*}$ and $x_{2}{ }^{*}$. Due to the fact that in conditional sentences a conditional link „And” was used, which in fuzzy logic is represented by the concept of the intersection (product) of fuzzy sets, the operation of aggregation of premises is reduced to seeking the value of the degree of membership to the relation $R_{N}$. This value is determined by using one selected rule of the fuzzy implication (a formula for the T-norm), which can be recorded as:

$$
\mu_{R_{N}}\left(x_{1}^{\star}, x_{2}^{\star}\right)=\mu_{A_{i} \cap B_{j}}\left(x_{1}^{\star}, x_{2}^{\star}\right)=T\left[\mu_{A_{i}}\left(x_{1}^{\star}\right), \mu_{B_{j}}\left(x_{2}^{\star}\right)\right]
$$

where: $R_{N}$ - fuzzy rule; $A_{i}, B_{j}$ - fuzzy sets for input variables; $T$ - selected formula on $T$-norm; $x_{1}{ }^{*}, x_{2}{ }^{*}$ - sharp inputs values.
Where the degree of membership to a relation $R_{N}$ equals 0 , the given rule is not started and does not take part in the process of inference.

The next stage is the application of the fuzzy implication method for each activated inference rule to determine its resultant conclusion. This process leads to a change in the shape of the membership function of fuzzy sets describing the resulting conclusions according to the degree of truthfulness of meeting the corresponding rules.

The concluding stage of the inference block is the aggregation of the conclusions of all the rules (aggregation of outputs). This action consists in combining the conclusions of the rules that are responsible for the shape of the resultant membership function $\mu_{\text {res }}(y)$. The first step determines, one by one, the modified membership functions of fuzzy sets for the output conclusions of the rules participating in the inference, and then the resulting fuzzy sets are summed up based on one of the formulas for the $S$ norm. The general form of the equation for aggregation of outputs can be presented as follows:

$$
\mu_{\text {res }}(y)=S\left[\mu_{R N}\left(x_{1}^{\star}, x_{2}^{*}\right)\right]
$$

where: $\quad \mu_{R N}-$ degree of truthfulness of activated rules; $S$ - selected formula on S-norm.

Table 2 compiles the selected fuzzy implications ( $T$ norms and S-norms), which are most frequently used for models built according to the assumptions of the Mamdani fuzzy model of inference (Mamdani, 1974; Mamdani, 1977). The fuzzy risk assessment module involves the basic applications of Mamdani T-norm and S-norm, that is minimum and maximum of Mamdani, respectively. The authors wrote about this assumption in (Plebankiewicz, \& Wieczorek, 2016).

The figures from Figure 9 to Figure 12 present a graphical interpretation of all sets of membership functions for the output variable $y$, namely the impact of an identified risk factor on a given component of the life cycle cost of a building object - IRF(Uph).

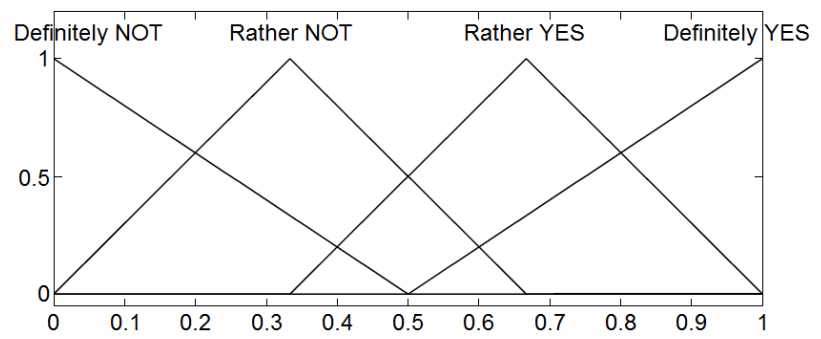

Figure 9: Membership function for the output variable $y$ - IRF(Uph), polygonal functions (piecewise linear) 
Table 1: Rule base for the inferential block

\begin{tabular}{ccclcccc}
\hline Rule No. & If $\left(\boldsymbol{x}_{1}\right)$ & And $\left(\boldsymbol{x}_{2}\right)$ & Then $(\boldsymbol{y})$ & Rule No. & If $\left(\boldsymbol{x}_{1}\right)$ & And $\left(\boldsymbol{x}_{2}\right)$ & Then $(\boldsymbol{y})$ \\
\hline 1 & $\mathrm{Vl}$ & $\mathrm{In}$ & Definitely not & 14 & $\mathrm{Av}$ & $\mathrm{Qi}$ & Rather yes \\
2 & $\mathrm{Vl}$ & $\mathrm{Ai}$ & Definitely not & 15 & $\mathrm{Av}$ & $\mathrm{Vi}$ & Rather yes \\
3 & $\mathrm{Vl}$ & $\mathrm{Av}$ & Rather not & 16 & $\mathrm{Qh}$ & $\mathrm{In}$ & Rather not \\
4 & $\mathrm{Vl}$ & $\mathrm{Qi}$ & Rather not & 17 & $\mathrm{Qh}$ & $\mathrm{Ai}$ & Rather not \\
5 & $\mathrm{Vl}$ & $\mathrm{Vi}$ & Rather not & 18 & $\mathrm{Qh}$ & $\mathrm{Av}$ & Rather yes \\
6 & $\mathrm{Ql}$ & $\mathrm{In}$ & Definitely not & 19 & $\mathrm{Qh}$ & $\mathrm{Qi}$ & Rather yes \\
7 & $\mathrm{Ql}$ & $\mathrm{Ai}$ & Rather not & 20 & $\mathrm{Qh}$ & $\mathrm{Vi}$ & Definitely yes \\
8 & $\mathrm{Ql}$ & $\mathrm{Av}$ & Rather not & 21 & $\mathrm{Vh}$ & $\mathrm{In}$ & Rather not \\
9 & $\mathrm{Ql}$ & $\mathrm{Qi}$ & Rather not & 22 & $\mathrm{Vh}$ & $\mathrm{Ai}$ & Rather yes \\
10 & $\mathrm{Ql}$ & $\mathrm{Vi}$ & Rather yes & 23 & $\mathrm{Vh}$ & $\mathrm{Av}$ & Rather yes \\
11 & $\mathrm{Av}$ & $\mathrm{In}$ & Rather not & 24 & $\mathrm{Vh}$ & $\mathrm{Qi}$ & Definitely yes \\
12 & $\mathrm{Av}$ & $\mathrm{Ai}$ & Rather not & 25 & $\mathrm{Vh}$ & $\mathrm{Vi}$ & Definitely yes \\
13 & $\mathrm{Av}$ & $\mathrm{Av}$ & Rather yes & & & & \\
\hline
\end{tabular}

Table 2: Selected rules for the intersection and sum operation of fuzzy sets

\begin{tabular}{ccc}
\hline Set & Fomula on T-norm & Formula on S-norm \\
No. & Minimum of Mamdani & Maximum of Mamdani \\
\hline 1 & $\mu_{A \cap B}=\min \left(\mu_{A}, \mu_{B}\right)$ & $\mu_{A \cup B}=\max \left(\mu_{A}, \mu_{B}\right)$ \\
& Algebraic product & Algebraic sum \\
2 & $\mu_{A \cap B}=\mu_{A} \cdot \mu_{B}$ & $\mu_{A \cup B}=\mu_{A}+\mu_{B}-\mu_{A} \cdot \mu_{B}$ \\
& Product of Hamacher & Sum of Hamacher \\
3 & $\mu_{A \cap B}=\frac{\mu_{A} \cdot \mu_{B}}{\mu_{A}+\mu_{B}-\mu_{A} \cdot \mu_{B}}$ & $\mu_{A \cup B}=\frac{\mu_{A}+\mu_{B}-2 \cdot \mu_{A} \cdot \mu_{B}}{1-\mu_{A} \cdot \mu_{B}}$ \\
& Product of Einstein & Sum of Einstein \\
4 & $\mu_{A \cap B}=\frac{\mu_{A} \cdot \mu_{B}}{2-\left(\mu_{A}+\mu_{B}-\mu_{A} \cdot \mu_{B}\right)}$ & $\mu_{A \cup B}=\frac{\mu_{A}+\mu_{B}}{1+\mu_{A} \cdot \mu_{B}}$ \\
\hline
\end{tabular}

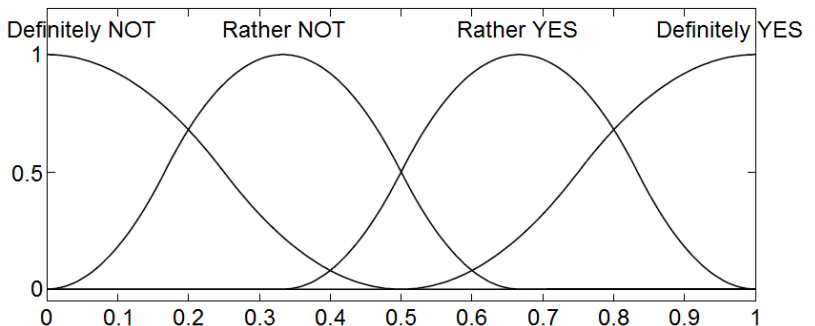

Figure 10: Membership function for the output variable $y-\operatorname{IRF}(U p h)$, complex functions (linear quadratic)

\subsection{Defuzzification}

The process of defuzzification is a mathematical operation performed on the resulting shape of the membership function (resultant fuzzy set) obtained after the aggregation of the conclusions of all inference rules. This operation aims

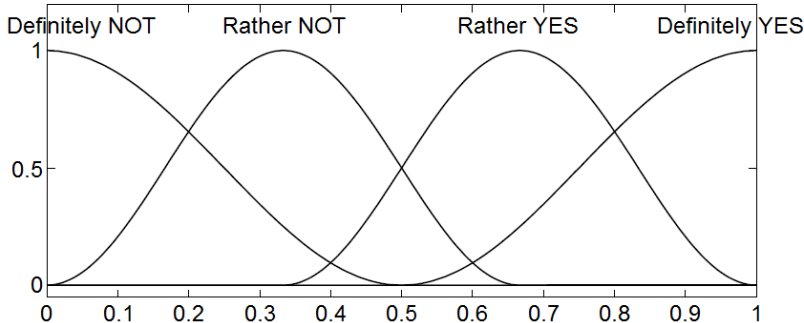

Figure 11: Membership function for the output variable $y$ - IRF(Uph), harmonic functions

to determine one, sharp value $y^{\star}$ which will adequately represent the output fuzzy set.

In fuzzy reasoning (according to Mamdani's approach), the final result can be formed in a number of ways (Kacprzyk, 2001; Piegat, 2003; Ross, 2009; Sivanandam, Sumathi, \& Deepa, 2007). Commonly used defuzzification methods include: first of maxima method, mid- 


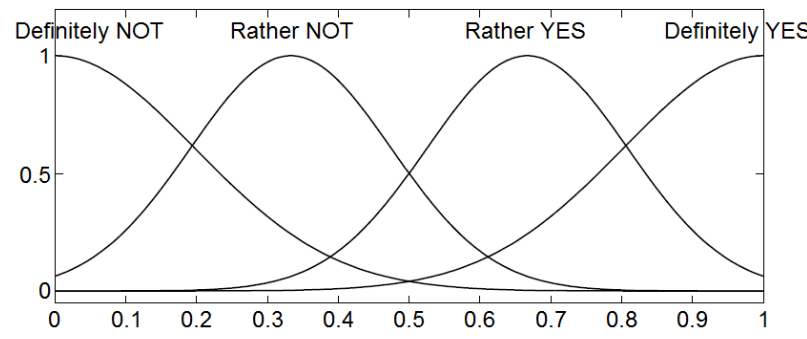

Figure 12: Membership function for the output variable $y-\operatorname{IRF}(U p h)$, Gaussian functions

dle of maxima method, last of maxima method, centre of gravity method, bisector area method, weighted average method, height method, centre of sums method and centre of largest area method.

All of the defuzzification methods mentioned above were analyzed for the possibility of their application in the defuzzification block of the fuzzy risk assessment module created. The process of the analysis, the results and conclusions were presented in the author's work (Wieczorek, 2018). It was noted, among others, that the use of each maxima method did not meet the main assumption that had accompanied the design stage of the inferencing block rule base. This assumption is mentioned in section 2.2 of this paper. Figure 13 and Figure 14 illustrates two example planes of solutions that were obtained using the rejected smallest of maxima method and centre of gravity method for the basic set of membership functions (polygonal functions).

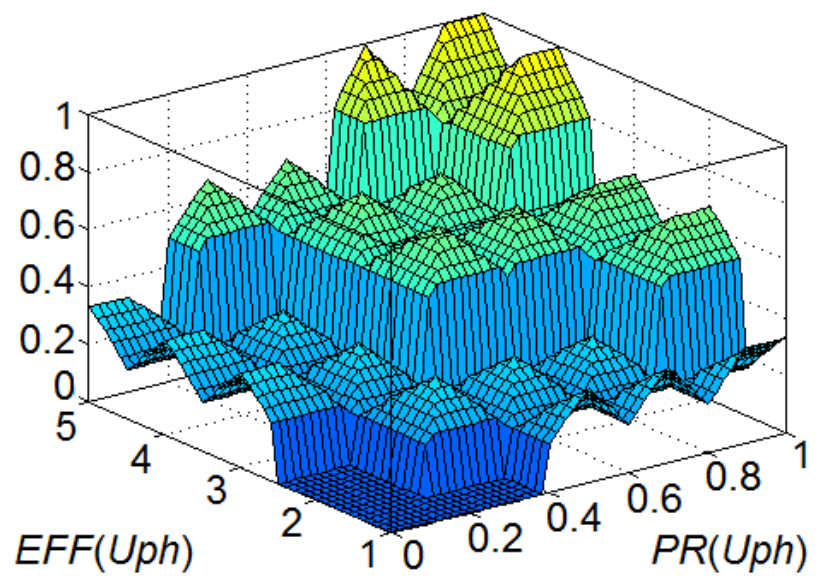

Figure 13: Surface solutions - smallest of maxima method

Two methods of defuzzification were eventually included in the defuzzification block, that is, the centre of gravity method and bisector area method. For the centre of gravity method the sharp output value is obtained on

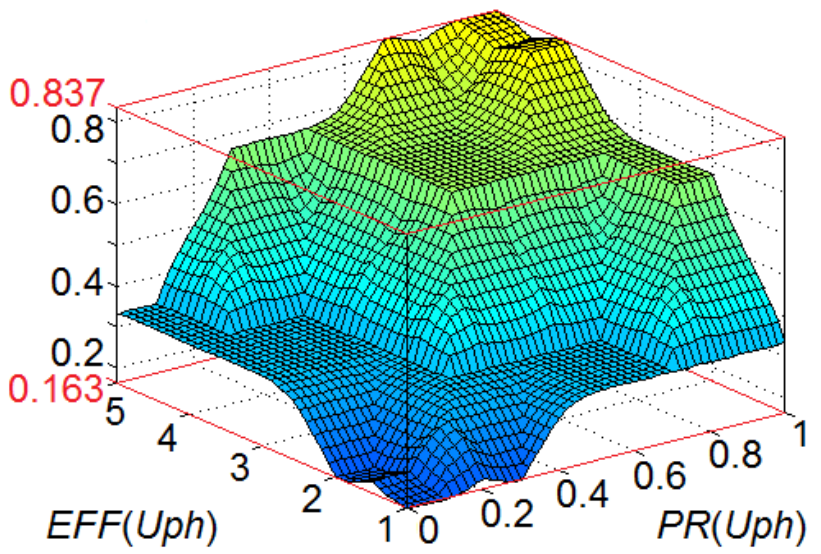

Figure 14: Surface solutions - centre of gravity method

the basis of the mathematical operation performed on the resultant membership function $\mu_{r e s}(y)$ :

$$
y^{\star}=\frac{\int_{y_{\min }}^{y_{\max }} y \cdot \mu_{r e s}(y) d y}{\int_{y_{\min }}^{y_{\max }} \mu_{r e s}(y) d y}
$$

And for the bisector area method the sharp output value is the result of searching for such value $y^{\star}$, that the surface areas under the left and right part of the resultant membership function $\mu_{r e s}(y)$ are equal. The basis for calculating the $y^{\star}$ value is the following equation:

$$
\int_{y_{\min }}^{y^{*}} \mu_{r e s}(y) d y=\int_{y^{*}}^{y_{\max }} \mu_{r e s}(y) d y
$$

A sharp output value (calculated by one or the other of the adopted methods) will be used to determine the resultant conclusion for which the membership value in $y^{\star}$ will be the maximum value. In this way, the evaluators of the risk factor will receive a final answer to whether they should take into account its impact on the corresponding component of the life cycle cost of the building and (when the answer is "rather yes" or "definitely yes") estimate the amount of the cost addition for risk according to the "model for the estimation of life cycle cost of a building object with risk factored in" procedure developed by Plebankiewicz, Zima and Wieczorek (Plebankiewicz, Zima, \& Wieczorek, 2017). 


\section{Multidimensional sensitivity study of the fuzzy risk assessment module}

In the fuzzy risk assessment module the basic set of membership functions are polygonal functions (internal symmetrical triangular functions and external left and right ones of $L$ and $\Gamma$ classes, respectively). This assumption was originally adopted in the author's work (Plebankiewicz, \& Wieczorek, 2016).

This paper examines the extent to which, in the fuzzy risk assessment module, the type of membership functions for input variables $x_{1}$ i $x_{2}$ and the output $y$, the rules of fuzzy implication to the process of aggregation of premises and aggregation of resultant conclusions, as well as methods for defuzzification the resultant value, affects the value of the output variable $y^{\star}$ obtained by calculation.

\subsection{Sensitivity analysis method}

Values of the variable $x_{1}$ (probability of a unwanted phenomenon) were adopted in the range from 0 to 1 (in increments of 0,1) and $x_{2}$ (effect of occurrence of a unwanted phenomenon) from 1 to 5 (in increments of 0,5). All 99 combinations of input variable values were simulated taking into account the combination for: 4 sets of membership functions (basic and 3 alternative), 4 sets of T-norms and $S$-norms presented in Table 2 (minimum and maximum of Mamdani, algebraic product and sum, product and sum of Hamacher, and product and sum of Einstein) and 2 defuzzification methods (centre of gravity method and bisector area method) possible to be applied. It follows from the above that the correctness of the operation of the fuzzy risk assessment module was evaluated for 3168 combinations of input variable values.

For each of the 3168 combinations, the sharp values of the output variable $y^{\star}$ were calculated. The parameters of individual membership functions were selected in accordance with the assumptions described in section 2.1 of the paper.

The results obtained were compared with each other for the same cross-section of input variables (32 cases in each of the 99 combinations of input variables). Subsequently, the following were calculated: arithmetic average $-m$, standard deviation $-s$ and coefficient of variation $-V$, which is a measure of variation just like standard deviation $(s)$, but, unlike $s$, it is a relative measure. This means that the coefficient of variation $V$ allows to compare the vari- ation of results in cases when the analyzed values are of different order. The coefficient of variation $V$ is expressed as a percentage, and it is calculated according to the following formula (Kot, Jakubowski, \& Sokołowski, 2011):

$$
V=\frac{s}{m}
$$

where: $\quad m$-arithmetic average, $s$ - standard deviation.

The authors of the article point out that the sensitivity test procedure described above was already applied in the case of a model built in accordance with the assumptions of Mamdani's fuzzy model of inference (Mamdani, 1974; Mamdani, 1977). The publication by (RadziszewskaZielina, \& Szewczyk, 2017) presents a sensitivity analysis for the fuzzy inference system which supports the control of partner relations between individual participants of a construction project. The authors of this publication have examined the extent to which the type of membership function used in this model affects the received output variable values.

\subsection{Results}

Table 3 presents part of the results obtained for 32 cases of combinations of sets of membership functions, rules of fuzzy implication to the process of aggregation of premises and aggregation of resultant conclusions, as well as methods for defuzzification the resultant value in the cross-section in which the probability of a unwanted phenomenon is $x_{1}=0,2$.

Table 3 contains about 2,27\% extract of all results obtained during the simulation of the operation of the fuzzy risk assessment module. For the results collected the following were determined: arithmetic averages $-m$, standard deviations $-s$ and the coefficients of variation $-V$. In Table 3 the results corresponding to the conclusions were marked "definitely not" (bolded italics), "rather not" (regular font) and "rather yes" (bold).

A coefficients of variation chart for all combinations of input variables and other elements affecting the results achieved in the fuzzy risk assessment module (sets of membership functions, sets of T-norms and S-norms according to Table 2 and defuzzification methods) are illustrated by Figure 15. In addition, Figure 15 graphically represents the values for the variable $y$ (impact of identified risk factor on a given component of the life cycle cost of a building object) - IRF(Uph) between neighboring resultant conclusions "definitely not", "rather not", "rather yes" and "definitely yes". 
Table 3: Values of the output variable $y$ for different variants of membership functions - part of the analyzed values of the input variables in section $x_{1}=0,2$

\begin{tabular}{|c|c|c|c|c|c|c|c|c|c|c|}
\hline \multirow{2}{*}{\multicolumn{2}{|c|}{$\begin{array}{c}\text { Set of: MF, } \\
\text { T- and S-norms, } \\
\text { defuzz. method }\end{array}$}} & \multicolumn{9}{|c|}{ Effect of occurrence of a unwanted phenomenon - EFF(Uph) } \\
\hline & & 1 & 1,5 & 2 & 2,5 & 3 & 3,5 & 4 & 4,5 & 5 \\
\hline 1 & $\begin{array}{l}\text { Polygonal } M F \\
\text { Mamdani, } C o G\end{array}$ & 0,1918 & 0,2912 & 0,2912 & 0,2912 & 0,3334 & 0,3334 & 0,3334 & 0,5000 & 0,5000 \\
\hline 2 & $\begin{array}{l}\text { Polygonal } M F \text {, } \\
\text { Mamdani, } B A\end{array}$ & 0,1800 & 0,2900 & 0,2900 & 0,2900 & 0,3300 & 0,3300 & 0,3300 & 0,5000 & 0,5000 \\
\hline$\cdots$ & $\cdots$ & $\cdots$ & $\cdots$ & $\cdots$ & $\cdots$ & $\cdots$ & $\cdots$ & $\cdots$ & $\cdots$ & $\cdots$ \\
\hline 11 & $\begin{array}{c}\text { Complex MF, } \\
\text { Algebraic, CoG }\end{array}$ & 0,1505 & 0,2118 & 0,2529 & 0,2923 & 0,3333 & 0,3333 & 0,3333 & 0,4278 & 0,5000 \\
\hline 12 & $\begin{array}{l}\text { Complex } M F \\
\text { Algebraic, } B A\end{array}$ & 0,1400 & 0,1900 & 0,2500 & 0,3000 & 0,3300 & 0,3300 & 0,3300 & 0,4000 & 0,5000 \\
\hline$\cdots$ & $\cdots$ & $\cdots$ & $\cdots$ & $\cdots$ & $\cdots$ & $\cdots$ & $\cdots$ & $\cdots$ & $\cdots$ & $\cdots$ \\
\hline 21 & $\begin{array}{l}\text { Harmonic } M F, \\
\text { Hamacher, CoG }\end{array}$ & 0,1630 & 0,2214 & 0,2595 & 0,3008 & 0,3333 & 0,3333 & 0,3333 & 0,4167 & 0,5000 \\
\hline 22 & $\begin{array}{l}\text { Harmonic } M F \text {, } \\
\text { Hamacher, } B A\end{array}$ & 0,1500 & 0,2100 & 0,2500 & 0,3000 & 0,3300 & 0,3300 & 0,3300 & 0,4000 & 0,5000 \\
\hline$\cdots$ & $\cdots$ & $\cdots$ & $\cdots$ & $\cdots$ & $\cdots$ & $\cdots$ & $\cdots$ & $\cdots$ & $\cdots$ & $\cdots$ \\
\hline 31 & $\begin{array}{l}\text { Gaussian } M F \\
\text { Einstein, } C O G\end{array}$ & 0,1469 & 0,1995 & 0,2544 & 0,2971 & 0,3337 & 0,3362 & 0,3423 & 0,4180 & 0,4941 \\
\hline 32 & $\begin{array}{c}\text { Gaussian } M F, \\
\text { Einstein, } B A\end{array}$ & 0,1200 & 0,1700 & 0,2500 & 0,3000 & 0,3300 & 0,3300 & 0,3400 & 0,3800 & 0,4900 \\
\hline & $m$ & 0,1585 & 0,2250 & 0,2618 & 0,2960 & 0,3324 & 0,3333 & 0,3365 & 0,4309 & 0,4977 \\
\hline & $s$ & 0,0229 & 0,0394 & 0,0190 & 0,0015 & 0,0005 & 0,0007 & 0,0018 & 0,0076 & 0,0010 \\
\hline & $V[\%]$ & 14,46 & 17,52 & 7,24 & 0,50 & 0,15 & 0,20 & 0,54 & 1,75 & 0,20 \\
\hline
\end{tabular}

After analyzing the results obtained for all 99 crosssections of coefficients of variation the authors noticed that:

- average value of coefficient of variation is $V_{m}=2,15 \%$,

- $\quad$ maximum value $V_{\max }=17,52 \%$ was obtained only in 1 out of 99 cross-sections analyzed (a cross-section where $x_{1}=0,2$ and $x_{2}=1,5$ ), which makes about 1,01 $\%$ of the total cross-sections studied,

- 75 out of 99 cross-sections ( $75,76 \%$ of the total crosssections studied), coefficient of variation values obtained a value smaller than the average value of the coefficient of variation $\left(V_{m}=2,15 \%\right)$,

- up to 64 out of all 99 cross-sections $(64,65 \%$ of the total cross-sections studied), coefficient of variation values were smaller than $1 \%$,
- up to 48 out of all 49 cross-sections for which the resultant conclusions are "rather yes" and "definitely yes" ( $97,96 \%$ of the cross-sections), coefficient of variation values were smaller than the average value of coefficient of variation, which was $V_{m}=2,15 \%$ (compare Figure 15),

- in only 1 out of 49 cross-sections for which the resultant conclusions are "rather yes" and "definitely yes" (2,04 \% of the cross-sections), coefficient of variation values slightly surpassed the average value of coefficient of variation $\left(V_{m}=2,15 \%\right)$ and equalled 2,49\% (a cross-section in which $x_{1}=0,9$ and $x_{2}=2$ ),

- in 7 out of 99 cross-sections $(7,07 \%$ of the total crosssections studied), coefficient of variation values exceeded $10 \%$, 


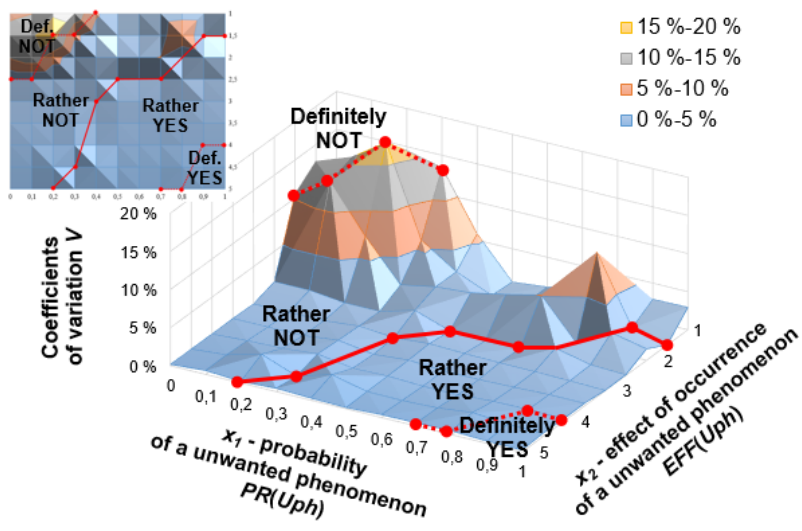

Figure 15: The map of the values of the coefficients of variation of the output variable $y$ depending on the value of the input variables $x_{1}$ and $x_{2}$

- the greatest variation in results occurred in the following cross-sections (input values $x_{1}$ and $x_{2}$, respectively): 0 and 1,5; 0 and 2; 0,1 and 1,5; 0,1 and 2; 0,2 and $1 ; 0,2$ and 1,$5 ; 0,3$ and 1 ,

- the greatest variation in results occurred in the crosssections for which the output conclusions indicate that there is no need to take into account the impact of the identified risk factor on the life cycle cost of a building - conclusions "definitely not" and "rather not” (compare Figure 15).

\subsection{Discussion and summary of research}

According to (Wasilewska, 2009; Wierzbiński, 2006), the values obtained for the coefficients of variation in the interval from 0 to $20 \%$ indicate poor variation of results for the output variable when the fuzzy risk assessment module employs different sets of membership functions for input variables $x_{1}$ and $x_{2}$ and output variable $y$, as well as various rules of fuzzy implication to the process of aggregation of premises, aggregation of resultant conclusions and methods of defuzzification the resultant value. In turn, (Zeliaś, Pawełek, \& Wanat, 2002) states that if the coefficient of variation $V$ does not exceed $10 \%$, the model shows insignificant differentiation for the obtained results.

The maximum value of the coefficient of variation, in one cross-section, reached $V_{\max }=17,52 \%$, and only in 7,07 $\%$ of the total cross-sections studied it was higher than 10 $\%$. In the remaining $92,93 \%$ cases, the values of the coefficients of variation did not exceed $10 \%$.

The results obtained were included in both intervals described above. The examination of the sensitivity of the fuzzy risk assessment module confirmed the high homogeneity of the results obtained.

\section{Conclusions}

On the basis of the multidimensional sensitivity study of the fuzzy risk assessment module in the life cycle of building objects described in this paper, it can be stated that the type of membership function sets for input variables $x_{1}$ i $x_{2}$ and the output variable $y$, as well as various rules of the fuzzy implication to the process of aggregation of premises, aggregation of resultant conclusions and methods of defuzzification the resultant value have an insignificant effect on the obtained value of the output variable $y$.

However, if one analyzes the results obtained for the value $y^{\star}$ representing the output fuzzy sets (resultant conclusions), one notices that the least convergent resultant conclusions that the fuzzy risk assessment module generates when one uses an alternative set III membership functions - Gaussian functions (especially in cross-sections where $x_{1}=0,1$ and $x_{1} \geqslant 0.3$ ). A similar observation can be made when using the centre of gravity defuzzification method (here especially in cross-sections where $x_{1} \geqslant 0.3$ ).

The authors recommend that the risk evaluator, when using the fuzzy risk assessment module in the life cycle of building objects, apply either sets of basic or alternative membership functions I and II (that is, except for Gaussian functions) and the defuzzification bisector area method to obtain the resultant value, using any set of fuzzy implication rules from Table 2.

\section{References}

[1] Aye, L., Bamford, N., Charters, B., Robinson, J. (2000). Environmentally sustainable development: a life-cycle costing approach for a commercial office building in Melbourne, Australia. Construction Management \& Economics, 18 (8), 927-934.

[2] Communication from the Commission to the Council and the European Parliament (2003, June 18). Integrated Product Policy (COM, 2003).

[3] Hasan, A., Vuolle, M., Siren, K. (2008). Minimisation of life cycle cost of a detached house using combined simulation and optimization. Building and Environment, 43 (12), 2022-2034.

[4] ISO 15686-5. (2008). Buildings and constructed assets. Service life planning. Part 5: Life cycle costing.

[5] Kacprzyk, J. (2001). Wieloetapowe sterowanie rozmyte, Warszawa: Wydawnictwa Naukowo-Techniczne.

[6] Kot, S. M., Jakubowski, J., Sokołowski, A. (2011). Statystyka, Warszawa: Difin. 
[7] Mamdani, E. H. (1974). Application of fuzzy algorithms for control of simple dynamic plant. Electrical Engineers, 121 (12), 15851588.

[8] Mamdani, E. H. (1977). Application of fuzzy logic to approximate reasoning using linguistic synthesis. IEEE transactions on computers, 100 (12), 1182-1191.

[9] Marszal, A. J., Heiselberg, P. (2011). Life cycle cost analysis of a multi-storey residential net zero energy building in Denmark. Energy, 36 (9), 5600-5609.

[10] Piegat, A. (2003). Modelling and Fuzzy Systems, Katowice: Akademicka Oficyna Wydawnicza EXIT.

[11] Plebankiewicz, E., Wieczorek, D. (2016). Rozmyta ocena ryzyka w cyklu życia obiektów budowlanych. Materiały Budowlane, 6 (526), 59-61.

[12] Plebankiewicz, E., Zima, K., Wieczorek, D. (2016). Life cycle cost modelling of buildings with consideration of the risk. Archives of Civil Engineering, 62 (2), 35-45.

[13] Plebankiewicz, E., Zima, K., Wieczorek, D. (2017). Quantification of the risk addition in life cycle cost of a building object. Technical Transactions, 5, 149-166.

[14] Radziszewska-Zielina, E., Szewczyk, B. (2017). Analiza wrażliwości modelu sterowania relacjami partnerskimi na zmiany funkcji przynależności zmiennych. Przegląd Naukowy - Inżynieria i Kształtowanie Środowiska, 26 (2), 219-225.

[15] Ross, T. J. (2009). Fuzzy logic with engineering applications, New Jersey: John Wiley \& Sons.
[16] Sivanandam, S. N., Sumathi, S., Deepa, S. N. (2007). Introduction to fuzzy logic using Matlab, Berlin: Springer.

[17] Skorupka, D. (2007). Metoda identyfikacji i kompleksowej oceny ryzyka realizacji przedsięwzięć budowlanych, W: 0 . Kapliński, Metody i modele badań w Inżynierii Przedsięwzięć Budowlanych, PAN KILIW, IPPT.

[18] Wasilewska, E. (2009). Statystyka opisowa od podstaw: podręcznik z zadaniami, Warszawa: Wydawnictwo SGGW.

[19] Wieczorek, D. (2018, July). Fuzzy risk assessment in the life cycle of building object - selection of the right defuzzification method. In: AIP Conference Proceedings (AIP Publishing), 1978 (1), 240005.

[20] Wierzbiński, J. (2006). Statystyka opisowa, Warszawa: Wydawnictwo Naukowe Wydziału Zarządzania Uniwersytetu Warszawskiego.

[21] Yi, H., Wen-jie, H. (2009). Analysis of the life cycle cost of the power plants based on analytic hierarchy process method, In: Information Management, Innovation Management and Industrial Engineering (International Conference on IEEE), 4, 639 642.

[22] Zeliaś, A., Pawełek, B., Wanat, S. (2002). Metody statystyczne: zadania i sprawdziany, Warszawa: Polskie Wydawnictwo Ekonomiczne. 